\section{A nuestros lectores}

Nuevo milenio, a punto del nœmero50 de la Revista ARQÉ

El equipo de $E$ diciones $A R Q$ preocupado por cubrir las necesidades de informaci-n para sus socios lectores, ha desarrollado durante el a-o 2001, una labor estratŽgica que consolida a la editorial como un canal de difusi-n permanente, sistem $\neq$ tico y abarcativo, de la arquitectura chilena. Estamos muy entusiasmados y orgullosos de nuestra gesti-n, la que estł generando un serie de contactos y materias que ustedes podrłnevaluar.

Les mencionamos algunos de estos logros:

\section{Presencia Internacional}

\section{Medios Virtuales}

El mundo de hoy carga consigo una dualidad para nuestros sentidos cuando se trata de elegir entre lo virtual y lo real, posibilidad que se hace aœn $m \neq s$ compleja a la hora de hablar de libros y revistas. Si bien es cierto, lo virtual cumple con las condiciones del mundo contemporłneo: globalizaci-ny determinaci-n,trayendo consigo los benepcios de una salida $¥ \neq$ pida y oportuna de producci-nintelectual y acadŽ mica, potenciando la posibilidad de reconocimiento universal y liderazgo, sin embargo a la hora de reßexionar no podemos dejar de pensar en lo agradable que es tener la libertad de poder elegir el momento, lugar y situaci-nen la que alargamos la mano para escoger el nomero de una revista o el libro que deseamos consultar, mostraro simplemente mirar. Dejamos al lector la inquietud y la elecci-n, cumpliendo con ofrecer las posibilidades -a nuestro alcance- para captarcada vez m‡ el interŽs en nuestra producci-n editorial.

Dos versiones para una revista http://www.scielo.cl

Se postul_la Revista ARQ, a la evaluaci-n de CONICYT, para ingresar al sitio scielo.Cl (Scientipc Electronic Library Online). E programa de edici-n electr-nica, es parte de las pol'ticas de CONICYT de fomento a la investigaci-n y difusi-n de sus resultados. Se incluyen en la colecci-n de Scielo Chile, revistas cient'pcas nacionales, previamente evaluadas, deacuerdo con criterios comunes, en todas las $¥$ reas del conocimiento.

R evista AR Q obtiene el reconocimiento en Octubre del 2001, estando a su disposici-n la primera revista $A R Q$ en su versi- $n$ digital, desde enero del 2002

Lo esperamos en http://www scielo.cl

Arquitectura chilena contemporłnea al mundo http://www.arq.c

La F acultad de Arquitectura de la Pontipcia Universidad $\mathrm{C}$ at-lica de $\mathrm{C}$ hile y $\mathrm{E}$ diciones $A R Q$ han adquirido recientemente el Portal de Arquitectura Chilena Contempor $\neq$ nea Arq.cl.

El objetivo es divulgar y promover la Arquitectura Chilena tanto a nivel naciona como internacional, generando por primera vez en Chile, la unipcaci-f de medios I'deres en lo que a difusi-n, educaci-n y promoci- $n$ de arquitectura se repere.

Arq.cl, es representante opcial en Chile de ICN (Internacional Competition Network) extensa red de difusi-n Internacional de
Arquitectura en 32 pa'ses.

Arq.cl congrega por ahora a 42 opcinas de arquitectura chilenas, con 206 arquitectos participantes, alrededorde $5.500 \mathrm{im} \neq$ genes, una base de datos de 3.000 inscritos en el sitio y un promedio de 500 visitas diarias. Cont¥ctenos en http://www.arq.cl

\section{Cattlogo 2002 de Ediciones ARQ} http://www.puc.cl

Usted podrł estar informado de nuestras publicaciones a travŽs del catłlogo ARQ. Vis'tenos www.puc.cl/(:Facultades, Escuela de Arquitectura, Publicaciones, Catłlogo 2000)

\section{Portal espa-ol de revistas de} arquitectura

\section{http://www.arquitextos.com}

Se ha respondido a la solicitud del se-or Antonio Garc'a, Director de Contenidos de Arquitextos.com, para ingresar la Revista ARQ a esteportalespa-ol, motordebosqueda de art'culos y sumarios de publicaciones especializadas dearquitectura.

Arquitextos.com reœnerevistas de gran prestigio internacional, tales como EI Croquis, 2G, Quaderns, On Dise-0, AV monograf'as, entre otras, lo que hace destacable el mencionar que ARO sea la primera revista extranjera en el sitio, desde el mes de enero de este $a-0$.

Lo esperamos en www.arquitextos.com

Presencia Internacional Editorial Ediciones ARQ en FIL 2001, MŽxic Tanto la exploraci-n de nuevos mercados editoriales como la consolidaci- $n$ de aquellos conocidos, revisten importancia a la hora de cumplir con lo propuesto por esta Casa E ditorial: Q̀a difusi-n, estudio y puesta en valor de la arquitectura, el dise-0 y el urbanismo de Chile y SudamŽricaÓ. A Pnes de noviembre del a-o 2001, se da inicio a una nueva etapa en el $¥$ rea de la difusi-n, comercializaci-n y desarrollo de las publicaciones en el extranjero. Pensando en la consolidaci-nde los proyectos propuestos, se abordan mercados internacionales con la asistencia de Ediciones ARO , representada por Elizabeth Bennett en el $¥$ rea editorial y Marianne Puchulœen la comercial, a la Feria del Libro de Guadalajara en MŽxico. En $90.000 \mathrm{mts} 2$, se desarrolla la $\mathrm{m} \neq \mathrm{s}$ din $¥$ mica y profesional de las ferias del libro de nuestro continente, destac $¥$ ndose la participaci-n mundial de autores, editores, libreros, bibliotecarios, distribuidores, proveedores de tecnolog'as y apasionados lectores de todo el mundo.

Un nutrido calendario de reuniones, nos permiti-constatar el interŽs demostrado porcasas editoriales de todo el mundo, tanto en torno a la arquitectura chilena como a la calidad de nuestras publicaciones, esto nos enorgullece y esperamos que en un corto plazo, las propuestas recibidas formen parte de los $\mathrm{pr}$-ximos proyectos ARQ Por ołtimo, quisižramos destacar la intervenci-n de los organizadores y participantes dela Feria, en especialP rochile, la $C \neq$ mara del Libro y el Consejo del Libro, cuya asesor'a y preocupaci-n permanentes, fueron fundamentales para el cumplimiento delasexpectativas planteadas.

Tenemos la grata obligaci-n de retribuir las menciones hechas por la $C \ddagger$ mara Chilena del Libro, a travŽs de sus representantes, a los medios de comunicaci-n: (̇̉ uscamos representaral pa's como un socio comercia coherente y rentable. Es impresionante la acogida que han tenido las universidades o los sellos independientes. Una de las solicitudes $m \neq s$ comunes tiene que vercon los textos de la Facultad de Arquitectura de la Universidad Cat-licaádDiario EL Mercurio, cuerpo C, Actividad Cultural 11/de diciembre 2001), a Prochile por su ilimitado apoyo y al Consejo Nacional del Libro con quien esperamos comprometer nuestro trabajo conjunto.

Con la satisfacci-n de haber cumplido con lo propuesto, queremos saludar a quienes nosacompa-arłnennuestrasnuevastareas: Trucatriche Distribuidores Para MŽxicoy Eeuu, J uan OÕ GormanLibrer'as, MŽxico; Gandhi Librer'as, MŽxico; Taller Sur Arquitectos, Guadalajara, MŽxico; Phaidon Press Limited, Inglaterra; Mosaic Press, Canadł; Grupo Noriega E ditores, MŽxico yTanais Ediciones S.a., Madrid, Espa-a.

\section{C on Liberalia S.A. a Europa}

A mediados del a-o 2001 se estableci-un convenio de distribuci-ral extranjero, en especial a Europa, con E diciones Liberalia SA

La participaci-n de la se-ora. Berta Concha como representante en diversos eventos a los que ha sido invitada $E$ diciones $A R Q$, en el viejo continente (Feria Liber en Madrid Espa-a y la prestigiada Feria del Libro de Frankfurt), ha permitido abrir un espacio para las publicaciones en este mundo de grandes lectores yestudiosos.

Gracias a ello se han producido un par de convenios de venta, que desde el punto de vista de la distribuci-m llegada a nuevos mercados, ponen en valor a todo un equipo que se siente comprometido a responde en pos de la difusi-nde la arquitectura chilena.

\section{Alianzas Estratž gicas E mpresas v/s} Universidad

Hoy en d'a se maneja el concepto de alianza estratŽgica, a modo de concentrar fuerzas en torno a los objetivos comunes de las organizaciones. Mantener constantemente el interžs por informar a quienes como profesionales requieren d'a a d'a de los œltimos avances, las tecnolog'as de vanguardia y productos del mercado se ha convertido en el objetivo del proyecto 这mpresa en L'neaÓque lleva a cabo ARQ . cla travŽs de sus sitio web.

Los medios ARQ, tanto escritos como virtuales, inician de este modo una modalidad inexplorada hasta el momento y que esperamos otorgue benebcios y puntos de encuentro tanto a arquitectos como empresarios.

Informaciones en Los Navegantes 1963, Pedro de Valdivia Norte, telŽfono 6865630 Fax 686.5634, e-mail arqedic@ puc.cl

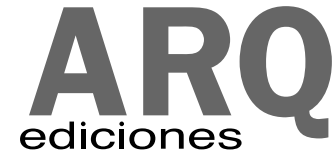

